out. For casting uranium, a high-frequency $(450$ kc./s.) induction high-vacuum furnace supplying $22 \mathrm{~kW}$. has been constructed, and metal specimens weighing 1-2 kgm. can now be melted and cast under a pressure of about $2 \times 10^{-2} \mathrm{~mm}$. of mercury. Since uranium exhibits dimensional instability, both on thermal cycling and under irradiation, a thermal cycling furnace has been built for the study of the behaviour of the metal under cycling conditions. The instability is known to be dependent upon the degree and type of preferred orientation, and a series of dilatometric experiments on preferred orientation in uranium containing $\mathbf{0 . 2 5}$ per cent chromium has been carried out. Additions to the equipment used for neutron diffraction work and for crystal structure studies included a Philips X-ray diffraction unit, a Geiger-counter diffractometer and several X-ray cameras, and studies have been made of hexamethylenetetramine, pentaerythritol, calcium hypophosphite, and mercury oxide. Other experiments conducted in the Physics Division have been concerned with the circular polarization of capture gamma-rays, and the gamma-rays emitted by fission fragments. The series of photo-nuclear reaction studies at Det Norske Radiumhospital using the betatron has been continued.

In the Chemistry Division, in addition to routine chemical and spectrographical analyses, the recovery of crsium-137 from fission products by co-precipitation with ammonium aluminium sulphate is being investigated. The study of the chemistry of plutonium has continued, and a sixty-four channel pulse height analyser, constructed in the electronics workshop, is now being used for routine analysis of uranium and plutonium mixtures.

During the second half of the year most of the work at the Establishment was concerned directly or indirectly with the Halden boiling-water reactor project, which was referred to in the report for 1954-55 (see Nature, 178, 1220; 1956). In 1956 the project received the official approval of the Norwegian Parliament, and the work is now well advanced. The reactor will be financed and built under the auspices of the Institutt for Atomenergi, but the design and planning are to be carried out by the Establishment. Many of the mechanical components will be produced by Norwegian firms, and negotiations are stated to be in progress with the United Kingdom Atomic Energy Authority and with the United States Government for the supply of the uranium fuel and heavy water, respectively. The reactor will be fuelled by seven tons of uranium distributed in a hexagonal lattice with a maximum of 325 fuel elements. The amount of heavy water needed as moderator and coolant is 15 tons. Initially, ten cadmium control stations will be installed, but the design allows for an additional nine if required. Although the plant will eventually supply process steam to a nearby paper mill, this is merely intended as an inexpensive way of dissipating the liberated energy, and the plant should really be regarded as an experimental engineering plant with a high degree of flexibility in design, permitting considerable variation in many of the basic specifications. The detailed discussion of the Halden project in the annual report includes a simplified schematic diagram of the reactor and associated equipment.

In the final sections of the report details are given of the various reports and publications issued by the Establishment during the period under review; of the reactor courses given at the Establishment; of personnel and accounts; of the numerous scientific meetings and conferences at which the Establishment was represented; and of the thirty-seven guest scientists representing twelve different nations who worked at the Establishment during part or the whole of the period covered by the annual report.

\section{THE BRISTOL MUSEUM}

\section{REPORT FOR 1956}

$T$ HE annual report* of the City of Bristol Museum is, as one has come over the years to expect, a well-produced, readable and stimulating publication reflecting the activities of one of Britain's outstanding provincial museums. Putting first things first, it deals with the personnel of committee and staff, with changes of persons and of posts, with new recruits and with degrees awarded, winding up with a gracious recognition of long services rendered-retirements after 22,22 and 26 years-a loyalty accorded and therefore clearly inspired. A novel post filled during the year is that of assistant curator in conservation, which called naturally for accommodation and equipment, a special laboratory and an iron treatment room. This is surely a realization of the best and most up-to-date in the museum tradition reflected in Dr. H. J. Plenderleith's recently published and remarkable text-book (see Nature, 179, 280 ; 1957).

In another field Bristol Museum continues to lead, namely, in its public education services, which achieve great things, not only among adults and schoolchildren of the area, both in classes and in leisure-time societies and clubs, but also among museum men and educationists from elsewhere, who seek practical experience and inspiration to transplant to their own institutions. Work continues on the permanent exkibits, inevitably calling for improvement and re-identification as research adds to the general field of knowledge, and the fact that half the report is devoted to $a$ list of accessions indicates both the lively outlook of the director and curators of Departments and the appeal the Museum exerts upon its supporters.

Temporary exhibitions, which do so much to enliven and attract, numbered no less than fifteen. Among the special features which have been continued with increasing success is the 'exhibit of the month', to which the city archivist has added quarterly exhibitions of Bristol playbills, concert notices, news-sheets of royal visits and so on, while the city librarian has provided material dealing with a local figure, the boy-poet Chatterton. The Museum finds a ready demand for its Quarterly Bulletin and for leaflets describing summer walks-which have an embarras. sing success-and winter lectures. The list of conferences, together with their home ports, is a most impressive one. Yet, with all these varied offerings to a public seven days each week, the staff has time to serve on a wide range of local and national committees and to conduct research and to publish the results in scientific and learned periodicals of standing. This is a full report betokening, on the part of all concerned, a full and doubtless satisfying life.

\section{A. Allan}

- City and County of Bristol. The City Museum: Report of the Committee for the year ended 31 December 1956. Pp. $22+2$ plates. (Bristol: City Museum, 1957.) n.p. 